\title{
AOR
}

Selected Papers of \#AolR2019:

The $20^{\text {th }}$ Annual Conference of the Association of Internet Researchers Brisbane, Australia / 2-5 October 2019

\section{PERCEPTIONS OF DARKNESS: MOBILE MEDIA AND THE EMBODIMENT OF RISK AND SAFETY IN THE URBAN NIGHT}

\author{
Jess Hardley \\ Murdoch University \\ Ingrid Richardson \\ Murdoch University
}

This paper explores the embodied experience of smartphone users in urban darkness, and considers how the geo-locative and network functionality of mobile media impacts upon the perception of safety and risk at night. City spaces at nighttime are often perceived as less safe, and the habitual trust we place in familiar strangers during the day can become imbued with caution, suspicion and fear. Women in particular are typically advised to reduce nighttime risk by remaining in well-lit, more populated areas, not travelling alone, and keeping mobile phones handy. Indeed, in contemporary popular culture, media coverage increasingly links heightened physical safety with the use of geo-locative mobile media. The case of Mollie Tibbetts' disappearance in lowa in 2018 after she went running early in the morning is one salient example of this - her mobile phone, Fitbit and social media accounts were not only used to help locate her, but the consequent coverage focused on the importance of carrying a mobile phone and sharing geo-locative data with friends or family as a way to better ensure one's safety (Bever, Lindsey, Wootson 2018; Spector 2018). This paper unravels the phenomenological dimensions of such accounts, and draws on original ethnographic data collected in Perth and Melbourne from 2015-2017, from surveys, interviews and tracking apps, to better understand the complex relation between mobile media use and women's corporeal and affective experience of the city at night. We examine how mobile devices as both communicative and location-aware interfaces are used to provide women with a perceived or 'felt' sense of bodily safety and security, and the potential implications this has for users' pedestrian traversal of the urban dark.

The effect of darkness on city-dwellers has been explored by a number of researchers concerned with urban safety, including Brands and Schwanen's (2014) sociological work on fear, trust and urban policy, and Hobbs et.al.'s (2005) study of violence, control

Hardley, J. and Richardson, I. (2019, October 2-5). Perceptions of darkness: Mobile media and the embodiment of risk and safety in the urban night. Paper presented at AolR 2019: The $20^{\text {th }}$ Annual Conference of the Association of Internet Researchers. Brisbane, Australia: AolR. Retrieved from http://spir.aoir.org. 
and the night-time economy. A recent conference on darkness convened in Norway (https://darknessconference2019.wordpress.com) covered such topics as folk literature, artificial intelligence, light pollution, religion, philosophy, architecture and nature, yet much of the research in this area neglects the impact of both the networked infrastructure of the city - what de Souza e Silva and Sutko (2009) term "net-local space" - and the place of mobile media in people's nighttime practices and their experience and perception of the urban dark. That is, although nighttime spaces and darkness are emerging as significant factors in urban media studies, to date academic research has tended "to overlook what happens when night falls" (van Liempt, van Aalst, and Schwanen 2014). It is the aim of this paper to begin addressing this oversight.

Throughout the paper, our conceptual and ethnographic approach is informed by Merleau-Ponty's (1945) work on habituation and proprioception, Ihde's (1998, 2009, 1993) postphenomenological take on the cultural specificity of the body-technology relation, and Weiss's (1999) feminist adaptation of the term intercorporeality. In line with this work, we argue that mobile media use comprises a particular relational ontology; that is, as we incorporate mobile devices as "fresh instruments" that become part of our pre-reflective grasp on the environment, mobile media practices are habituated as "knowledge in the hands" (Moores 2009), and thus are intrinsic to our embodied beingin-the-world. As we will show, a postphenomenological approach to ethnographic research and mobile media use allows us to account for gendered experiences and perceptions of urban space, darkness and risk. Through a close mixed-methods analysis of our participants' use of their mobile phones at night, we explore how mobile devices have modified women's embodied metaphors of darkness both in terms of their geo-spatial and proprioceptive awareness of local space, and the ambient sense of connection afforded by social networking platforms and mobile apps, or what Farman (2012) calls "social proprioception". Our research data reveals that darkness affects the way women deploy proprioceptive vigilance and incorporate mobile devices into their bodily schemata, while at the same time mobile user-habits changed participants' affective and visceral awareness of immediate and potential risk. In each case the presence of the mobile phone "in the hand" was accompanied by a varying spectrum of trust and apprehension that was felt in the body - from mistrust in the fluctuating reliability of geo-location apps and network connectivity, to faith in the ambient everpresence of friends and family just a phone call or direct message away.

The theme of "trust" runs as a thread through this paper, as we unpack the mistrust city dwellers have of the urban dark and how mobile media perceptually ameliorates this embodied sense of risk by extending users' communicative reach via location-aware interfaces. At the same time, the trust users place in their mobile devices is explored as a paradoxical tension between the reassurance afforded by perpetual connection, and concurrently, the anxiety generated by fallible tracking apps, network interruptions and GPS dysfunctionality. 


\section{References}

Bever, Lindsey, Wootson, Cleve R. 2018. "Fitbit May Be Key to Finding lowa Student Who Went for a Jog Last Week and Hasn't Been Seen since." The Washington Post, July 27. https://www.washingtonpost.com/news/truecrime/wp/2018/07/27/fitbit-data-may-be-key-to-finding-the-iowa-college-studentwho-went-for-a-jog-and-vanished/?utm_term=.614084e605ee.

Brands, Jelle, and Tim Schwanen. 2014. "Experiencing and Governing Safety in the Night-Time Economy : Nurturing the State of Being Carefree." Emotion, Space and Society 11. Elsevier Ltd: 67-78. doi:10.1016/j.emospa.2013.08.004.

de Souza e Silva, Adrianna, and D. Sutko (2009) Digital Cityscapces. NewYork: Peter Lang.

Farman, Jason. 2012. "Historicizing Mobile Media: Locating the Transformations of Embodied Space". In N. Arceneaux and A. Kavoori (eds) The Mobile Media Reader New York: Peter Lang, pp. 9-22.

Hobbs, Dick, Phil Hadfield, stuart Lister and Simon Winlow. 2005. "Violence and Control in the Night-Time Economy." European Journal of Crime, Criminal Law and Criminal Justice 13(1): 89-102.

Ihde, Don. 1993. Postphenomenology: Essays in the Postmodern Context. Evanston, Illinois: Northwestern University Press.

- 1998. Philosophy of Technology: An Introduction. New York: Paragon House.

_ 2009. Postphenomenology and Technoscience: The Peking University Lectures. New York: Suny Press.

Merleau-Ponty, Maurice. 2014 [1945]. Phenomenology of Perception. London: Routledge.

Moores, Shaun. 2009. "That Familiarity with the World Born of Habit: A Phenomenological Approach to the Study of Media Uses in Daily Living." Interactions: Studies in Communication and Culture 1 (3): 301-12. doi:10.1386/iscc.1.3.301.

Spector, Nicole. 2018. "Scared to Run Alone? Women Runners Share Their Best Safety Tips." Better, November 13. https://www.nbcnews.com/better/health/scared-runalone-female-runners-share-how-they-stay-safe-ncna935186.

van Liempt, Ilse, Irina van Aalst, and Tim Schwanen. 2014. "Introduction: Geographies of the Urban Night." Urban Studies, October, 0042098014552933-. 
doi:10.1177/0042098014552933.

Weiss, Gail. 1999. Body Images: Embodiment as Intercorporeality. New York: Routledge. 